Humpback whales are present in all oceans. Although their population was decimated during the 20th century by industrial whaling, their numbers are now slowly increasing. This has been observed for both the North Atlantic and the North Pacific humpback whale populations. More investigations are needed to confirm this positive trend regarding South hemisphere stocks. Observations will also be useful to better estimate the effects of human activities, such as climate change, fisheries, oil prospection, and marine traffic on their population. The high mobility of this species, both during their migration and during breeding seasons, means that people from all countries have to work together towards a common objective: collect more data to create more knowledge to better protect them.

This is especially required in the South Western Indian Ocean, where islands belonging to many different countries are dispersed on their migration pathways. For the past 10 years, we have been working in collaboration with the Association Cetamada on this population in order to describe their distribution, their interactions, their behaviors, and their habitats. We wanted to share our methods and our results with other researchers in this geographic area, from which came the idea of creating an international conference.

We were very surprised that no scientific conferences were specifically dedicated to humpback whales. Many conferences are general to all marine mammal species or specific to methods and observation techniques. We therefore started to think about creating a place where researchers could come to exchange specifically about this species. Two main reasons were behind this idea. Firstly, humpback whales are probably baleen whales, which are the most observed whales across the globe. This means that datasets are increasing in size and quality, and could be shared to provide new results. Secondly, research on this species can be carried out using large multi-disciplinary approaches, including animal biology, marine ecology, ethology, genetics, applied mathematics and engineering.

Bringing together experts from different areas but all working on humpback whales and their marine ecosystems was the strong motivation behind the Humpback Whale World Congress that we created and organized with the Association Cetamada. The first session was held on Sainte Marie Island (Madagascar) from June 29 to July 3,2015 . More than 70 professionals and students from 16 countries gathered at this congress. Renowned keynote speakers came from across the world, and 10 oral sessions were planned to give the chance to speakers to show their original methods and their recent results, making this conference a great success.

This special issue of the Journal Madagascar \& Development is a compilation of the best presentations of this congress.

\title{
Olivier Adam
}

Professor

Sorbonne University, Paris

olivier.adam@u-psud.fr 


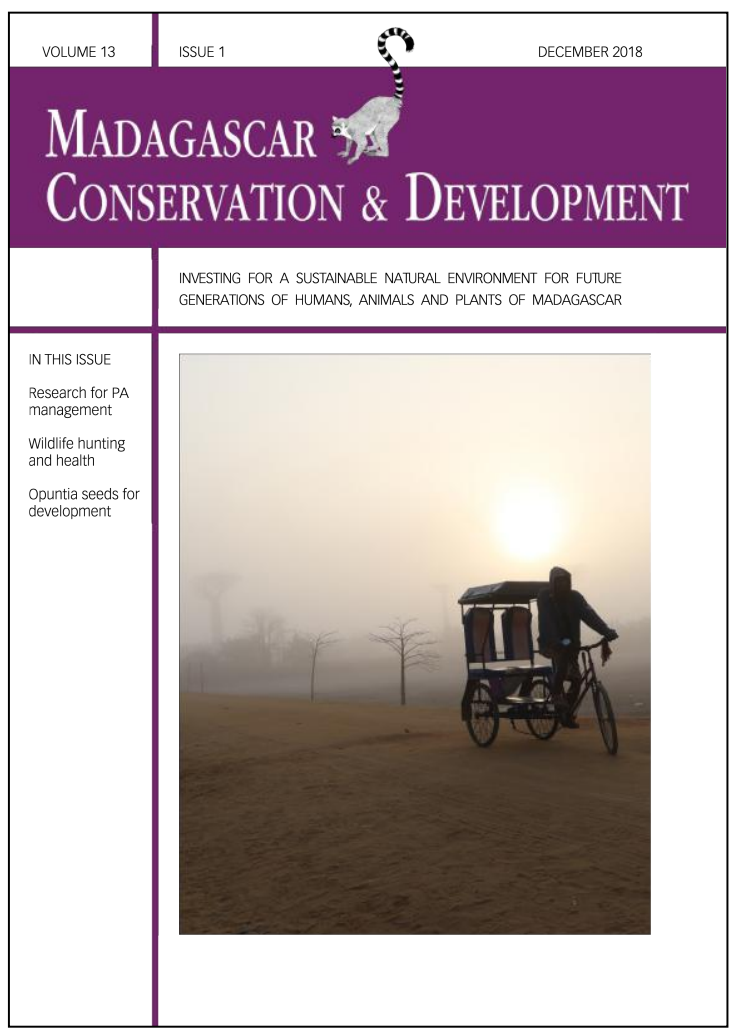

Madagascar Conservation \& Development is the journal of Indian Ocean e-Ink. It is produced under the responsibility of this institution. The views expressed in contributions to MCD are solely those of the authors and not those of the journal editors or the publisher.

All the Issues and articles are freely available at http://www.journalmcd.com

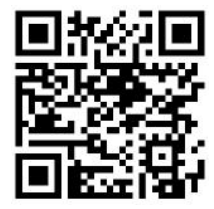

Contact Journal MCD

info@journalmcd.net for general inquiries regarding MCD funding@journalmcd.net to support the journal

Madagascar Conservation \& Development Institute and Museum of Anthropology

University of Zurich

Winterthurerstrasse 190

$\mathrm{CH}-8057$ Zurich

Switzerland

Indian Ocean e-Ink

Promoting African Publishing and Education

www.ioeink.com

Missouri Botanical Garden (MBG)

Madagascar Research and Conservation Program

Missouri Botanical Garden

BP 3391

Antananarivo, 101, Madagascar 